\title{
TOWARD ADVERSARY ANTHROPOLOGIES, OR, HOW TO BUILD YOUR OWN REVOLUTIONARY INFRASTRUCTURE
}

\author{
MARCEL LAFLAMME \\ University of Washington \\ (D) http:/ / orcid.org/0000-0002-7489-4233 \\ DOMINIC BOYER \\ Rice University \\ (D) http:/ / orcid.org/0000-0001-8944-406X
}

Some three decades ago now, Ulf Hannerz (1987) wrote an appreciation of what he called "anthropology's other press": periodical publications that were neither flagship journals like American Anthropologist nor devoted to a specific subfield, but that were sustained by an essentially local scholarly community. Hannerz (1987, 214) recounts one characterization of these journals as "the samizdat of anthropology," noting that they

often appear at somewhat irregular intervals, for which their editors make apologies; they tend to be mimeographed or produced by some other less prestigious technique, although some are quite elegantly printed; and many are short-lived, while those which are less ephemeral may have changed name and design at least once.

Despite these putative faults, Hannerz treats this "other" press as worthy of careful consideration. He argues that its function is, in part, that of training professionals to eventually engage in weightier publishing endeavors. Yet he goes on to complicate this teleological narrative, noting that these journals can also serve as a 
space for play: "The style can be more daring, or more familiar in tone; you may use sources of an unconventional sort; you may play on a wider range of the collective consciousness; you may allow yourself to speculate more freely" (Hannerz 1987, 218). At their most ambitious, he suggests, such publications might give rise to "adversary anthropologies" (Hannerz 1987, 218) that challenge the doxa of the day and torque the discipline in new directions.

The same year that Hannerz published this article, graduate students at Syracuse University founded New Horizons in Adult Education, arguably the first scientific journal to be published in electronic form (see Hugo and Newell 1991). As this new mode of publishing gained momentum, researchers began to argue that low-cost online distribution could radically expand access to the scholarly record. Yet the open-access movement has never really caught fire in anthropology beyond a fervent corps of true believers. Why, we wonder, might that be so? People, of course, are busy, and the intricacies of different publishing models are enough to deter anyone save the most bloody-minded. Beyond that, though, we speculate that, for many, open access seems to be a technical problem rather than a basis for political mobilization. From the perspective of those thirsting for radical change in the academy and beyond, there is surely something a bit precious about the open-access movement's preoccupation with how articles get downloaded. So, for those of us who do see a more broadly revolutionary potential in openaccess initiatives, it's up to us to make the case for how it could be unlocked.

As the fiery reckonings of \#HAUtalk have insisted (e.g., Mahi Tahi 2018; Todd 2018; West 2018), the open-access movement in anthropology needs to open itself more fully to decolonizing, antiracist, and feminist currents within the discipline. We are writing in this spirit, in the hope that open access can serve as an accelerant for more radical kinds of social change (and in recognition of all that open-access advocates can learn from those who are already bringing such change about). Thus, rather than foregrounding liberal formulations of freedom and property on which discussions of open access so often rely, we propose to approach open access as a kind of "revolutionary infrastructure" (Boyer 2017) that redirects energies presently locked into the status quo toward fissures of breakthrough and transformation. Proof of this potential already abounds. New, hybrid publications like Limn are expanding the circulation of anthropological insight, while organizations with established journals are turning to DIY forms like the zine (see Tanis 2017). Scholarly blogs like Allegra Lab, Anthrodendum, Footnotes, and Somatosphere have meanwhile lapped journals as the liveliest nodes of disciplinary debate, publishing vital scholarship but also constituting publics whose 
participants can find allies for bold political programs. We believe that anthropology needs more of these projects, which regard open access as the default but nurture activist commitments that extend far beyond it. Such projects can use next-generation technologies to nurture the localism that makes them unique, while allowing a wider audience to listen in and learn. By reinventing anthropology's "other" press for our digital era, we can rebuild anthropological communication from the ground up.

There is some irony, of course, in issuing this call in the pages of one of the discipline's most prominent journals. But it was not so long ago that Cultural Anthropology (CA) was itself an upstart, and that spirit of restlessness has been carried forward in recent years with new multimedia capabilities and short-form genres. Still, CA remains enmeshed in a journal system that has come under criticism for its sluggishness, elitism, and opacity, even as scholars have revealed that system to be more historically contingent than we might think (Csiszar 2018). Thus, our aim here is not to fetishize the journal form or to insist on its reproduction. Rather, we want to emphasize that the real promise of open access is its ability to amplify conversations that have not yet found recognition in mainstream channels and to thereby catalyze material transformations of a deeply unequal world. If you are not seeing your interests, ethics, and politics represented in the leading journals of your discipline, then perhaps it is time to advance your own adversary anthropologies. Here are some ideas for how to go about it.

\section{PATHWAYS TO SCHOLAR-LED PUBLISHING}

In the first of a series of blog posts on starting an open-access journal, Martin Eve (2012) argues that "what takes the time, energy, and willpower is to get the social, rather than technical aspects sorted." We largely agree. Initiating a new publishing project is, in the first instance, about recruiting a motivated, dependable, diverse group of co-conspirators. It also entails a substantive discussion about the project's goals: what need will it meet, who will its audience be, and what will make it different from other projects with a similar focus? What values will guide the project, both in terms of its intellectual output and its day-to-day operations? Decisions about which tools to use, what form of governance to adopt, and so on should be made in the context of active, spirited debate about what those values require.

Of course, the technical aspects of a publishing project also demand attention, although our sense is that too often those aspects are what scare scholars off from launching a new project at all. Exhaustive lists of the things that legacy 
publishers do (e.g., Anderson 2018) can intimidate scholars into thinking that turning a project over to the pros is the only viable option. But we propose an alternative or adversary reading of such lists, as blueprints that can be reverseengineered to keep scholars at the center of their publishing endeavors. This is not to discount the expertise that publishing professionals undeniably have. But it is to challenge their monopoly over the means of production in light of new digital tools paired with an ongoing commitment to learning and collaboration (see Adema and Moore 2018).

\section{Path One: Starting a journal}

The model of journal publishing with which most of us are familiar involves soliciting manuscripts that are reviewed on an exclusive and anonymous basis by a small number of reviewers selected by the journal's editors. Upon their eventual acceptance, these manuscripts are placed into a production process that might include copyediting and typesetting before being published in their finished form. Many open-access journals operate in just this way; what differentiates them from subscription journals is the fact that the published articles are freely available to read and, in many cases, to reuse in derivative works like translations.

As Figure 1 shows, starting a new journal on this model means identifying people to serve in various editorial roles and mapping out how they will work together. It usually also means selecting a piece of software known as a journal management system and deciding who will be responsible for it. Open Journal Systems (OJS), first released in 2001, is one of the most widely used journal management systems for open-access journals; as of this writing, CA uses OJS to manage submissions and reviews, and in 2019 the journal will begin using a muchimproved new version of OJS as its primary publication platform.

A journal that wants to use OJS has a few options, depending on available resources. For $\$ 850$ per year, the Public Knowledge Project’s Publishing Services division will host an instance of OJS and take care of any necessary upgrades and backups. If your team has some technical expertise, you can host your own instance on a local server: a less expensive and fully customizable option, but one that leaves you responsible for ongoing support. Perhaps the best option, from our point of view, is to partner with a library publisher; you can find an annually updated directory at https: / / librarypublishing.org/resources. Most library publishers provide free hosting for journals with some connection to their institution, and many provide other services too. Even if you aren't at an institution with a library publishing program, don't write this sector off: a growing number of 


\section{How To STarT an OPEN ACCESS JOURNAL

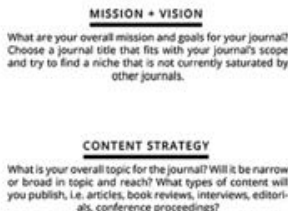

FILE FORMATS

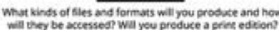

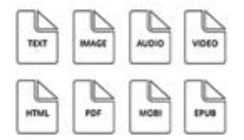

PERodicity

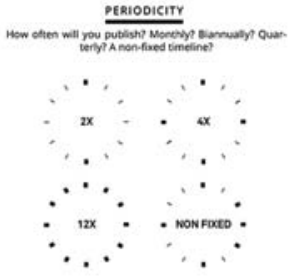

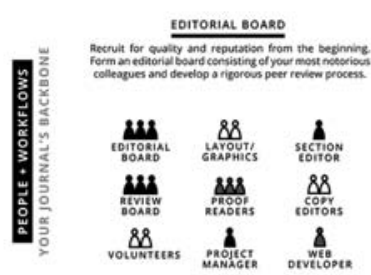

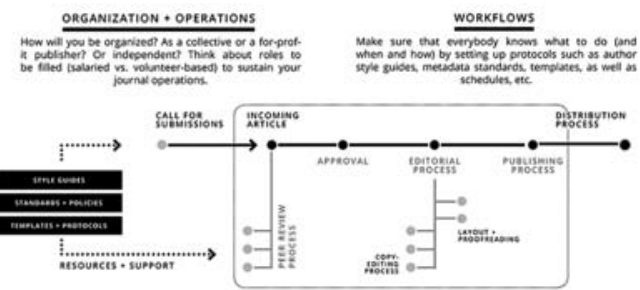

Figure 1. Excerpt from "How to Start an Open-Access Journal," a poster by the Hybrid Publishing Lab at Leuphana University of Lünenburg. See the complete poster at http:/ / hybridpublishing.org/2014/07/infographic-how-to-start-an-open-access-journal for a detailed walk-through of starting an open-access journal. Image licensed under CC BY.

library publishers will work with external partners, although they may charge a fee to recover some of their costs.

To be clear: OJS is not the only journal management system out there (see Michael 2018 for a recent review). Open-access journals like Tipiti and Teaching and Learning Anthropology are built on top of digital repositories maintained by libraries. Companies like Scholastica emphasize turnkey simplicity through a software-as-a-service model. And new platforms continue to be developed, including Janeway (which powers the Open Library of Humanities) and Vega (which has a particular focus on multimedia content and interactivity). Many of these platforms have both hosted and self-hosting options, allowing users to decide on the tradeoff 
between providing their own infrastructural labor or paying a modest sum for someone else's.

Timothy Elfenbein $(2014,295)$ cautions that, too often, open-access advocates focus on the accessibility of published content and gloss over other priorities like discoverability and persistence. For this reason, if starting a journal is your aim, we do not recommend simply throwing up a website using an off-theshelf platform like WordPress. Such a site will not be well-integrated into research infrastructures like Google Scholar, meaning that the research you publish runs the risk of getting overlooked by scholars outside your core network. Here, again, working with a library publisher can save you time and money; knowledgeable library staff can handle tasks like reaching out to indexers, who will place your journal in specialized scholarly databases, and registering digital object identifiers (DOIs), which will direct future readers to your content even if the journal is eventually hosted somewhere else.

\section{Path Two: Beyond the journal}

Today, a growing chorus of disruptors has the journal form in their sights. They express frustration with the time it takes for an article to make its way from submission to publication, and with a peer review process that can be marred by error and bias. They question the hoarding of prestige by a small number of influential publications, and the use of that prestige (or its quantitative analogues) as a proxy for merit in high-stakes decisions about tenure and promotion. They also note the vulnerability of the existing system to capture by publishers, who can charge libraries whatever they want because researchers insist on access to particular titles for which no substitute will do. For these reasons and more, there is new enthusiasm in some quarters for steering scholarly communication beyond the journal system, while aiming to ensure that the functions journals presently serve will continue to be carried out. In this postjournal world, the standalone article "ricochets around a rich ecosystem of modular services, acquiring new metadata, comments, stamps, links, citations, annotations, and edits as it goes" (Priem and Hemminger 2012).

Without endorsing the platform-capitalist vision of a publishing marketplace that many of these disruptors espouse, new open-access projects can further their revolutionary aims by exploring alternatives to the model of the journal described in the previous section. You might decide that the ease of setting up a blog-style forum is worth the tradeoffs in terms of discoverability and persistence; social media can help to close the gap on the former score, while web archiving initia- 
tives like Webrecorder are making strides toward the preservation of dynamic content. You might participate in one of the experiments that are underway around peer review (see Tennant et al. 2017), many of which invite reviewers to provide feedback on a manuscript after it is already online for the world to see. You might go on to curate a selection of these writings into an overlay journal - a cohesive playlist of sorts — without laying exclusive claim to them. (Check out a platform called PubPub if this model appeals to you.) Innovations like these challenge our received notions of what a publication looks like, but they speed up the dissemination of new ideas and they show the communitybased work of thought being refined - pushing back against the sometimes alienating polish of the finished product.

Indeed, it is fair to say that contemporary challenges to the journal system are motivated, in part, by a desire to make the process of knowledge production more visible and more collaborative. In the hard sciences, the push for open data has been driven by norms of reproducibility that anthropologists do not necessarily share. But tools like the Open Science Framework could be used in a more critical, interpretive vein to work through research data marked by varying degrees of rawness. As Philip Mirowski $(2018$, 190) reminds us, such data is not "inherently fungible," which is why other projects like Mukurtu and the Platform for Experimental and Collaborative Ethnography are working to ensure that context does not drop out as data travels. We believe that designing a publishing project around tools like these could invite new forms of intimacy with the research worlds that each of us inhabit and establish a norm of getting our research materials off of our hard drives and back into the hands of the communities to whom they ultimately belong.

\section{CONCLUSION}

We want to close with a few friendly recommendations for senior scholars who are willing to become allies in the production of adversary anthropologies. First of all: don't stay on the sidelines. Your participation can be extraordinarily valuable in the process of establishing and gaining traction for new publishing projects. While the $H A U$ scandal showed how a lack of transparency and robust oversight can lead to abuse, one more positive lesson that might be salvaged from the project is that a group of established scholars were able to help boost the reputation of a publication led by a graduate student such that it became one of our discipline's most influential journals in just a few years' time. Your involvement matters, and yet we hasten to add a second point: this isn't about you. Senior 
scholars are more likely to be welcomed as partners in the fashioning of revolutionary infrastructures if they do not assume that they should be in charge and do not use new open-access projects as vehicles for their own intellectual agendas. We believe that senior scholars can accelerate a bottom-up revolution in anthropological publishing - if they are willing to commit themselves to a future-tilted, intergenerational ethics of collaboration. In other words, if you're fortunate enough to be a tenured faculty member in the brave new world of the twentyfirst-century academy, congratulations are in order: you've made it! There is no need to anxiously tend to your achievements or legacy. Rather than striving to continue accumulating academic capital, why not invest time in sending the elevator back down? Or, better yet, in helping to build more elevators.

Our third call to action is especially aimed at faculty serving on hiring, evaluation, and tenure committees: help to loosen the grip of the so-called top journals (and yes, that includes this one). The legitimizing power of these journals, most of which are published in English and based in the global North, is sustained by myriad everyday acts of evaluation at institutions around the world (e.g., Lee and Lee 2013). Wherever you can, move away from expecting publications in one of three or four legacy titles as the ticket to a job offer or promotion. Instead, help to build recognition of the no less excellent work being published in new openaccess ventures, especially if they are published in languages other than English and/or based in the global South (see Piron et al. 2016 for one inspiring example). Be willing to serve on their editorial boards if you are invited to join them, offer your time and networks for peer review, and cite their output in your own publications. Put your labor into opening horizons rather than gatekeeping privilege.

Finally, and this is a more radical proposal, consider taking steps to starve the system. The journal system as we know it depends on voluntary labors of writing, reviewing, and editing. By the time one has reached tenure or equivalent status, those labors truly are chosen, rather than required. It's important, therefore, for senior scholars to be strategic about where they spend their energies. What if anthropologists in secure, tenured jobs were to take a \#StarveTheSystem pledge, publicly stating that they would no longer write, review, or edit for paywalled journals in the hands of predatory commercial publishers like Elsevier and Wiley? Such a pledge, if widely adopted by senior scholars, would hollow out the legitimacy of the existing journal system and create an environment ripe for experimentation and renewal. It would also compel scholarly societies like the American Anthropological Association to reconsider their reliance on cor- 
porate royalties and to become actively engaged in the work of forging open futures.

There is, in short, a role for each of us in the making of adversary anthropologies. Let's get busy!

\section{ACKNOWLEDGMENTS}

Thanks to Tim Elfenbein, Nick Estes, and Ryan Jobson for their valuable comments on this editorial.

\section{REFERENCES}

Adema, Janneke, and Samuel A. Moore

2018 "Collectivity and Collaboration: Imagining New Forms of Communality to Create Resilience in Scholar-Led Publishing.” Insights 31. https://doi.org/ Anderson, Kent 10.1629/uksg. 399 .

2018 "Focusing on Value - 102 Things Journal Publishers Do (2018 Update)." Scholarly Kitchen, February 6. https://scholarlykitchen.sspnet.org/2018/02/ Boyer, Dominic 06/focusing-value-102-things-journal-publishers-2018-update.

2017 "Revolutionary Infrastructure." In Infrastructures and Social Complexity: A Companion, edited by Penny Harvey, Casper Bruun Jensen, and Atsuro Morita, 174-86. New York: Routledge.

Csiszar, Alex

2018 The Scientific Journal: Authorship and the Politics of Knowledge in the Nineteenth Century. Chicago: University of Chicago Press.

Elfenbein, Timothy W.

2014 "Cultural Anthropology and the Infrastructure of Publishing." Cultural Anthropology 29, no. 2: 288-303. https://doi.org/10.14506/ca29.2.06.

Eve, Martin Paul

2012 “Starting an Open Access Journal: A Step-by-Step Guide, Part One.” Personal website, July 10. https://www.martineve.com/2012/07/10/starting-an-open-

Hannerz, Ulf access-journal-a-step-by-step-guide-part- 1 .

1987 “Anthropology's Other Press: Training Ground, Playground, Underground." Current Anthropology 28, no. 2: 214-19. https://doi.org/10.1086/203520.

Hugo, Jane, and Linda Newell

1991 “New Horizons in Adult Education: The First Five Years (1987-1991)." Public-Access Computer Systems Review 2, no. 1: 77-90. https://journals.tdl.org/pacsr/ index.php/pacsr/article/view/6032.

Lee, Hikyoung, and Kathy Lee

2013 "Publish (in International Indexed Journals) or Perish: Neoliberal Ideology in a Korean University." Language Policy 12, no. 3: 215-30. https://doi.org/ 10.1007/s10993-012-9267-2.

Mahi Tahi

2018 “An Open Letter to the HAU Journal's Board of Trustees." Association of Social Anthropologists of Aotearoa/New Zealand website, June 18. http:// www.asaanz.org/blog/2018/6/18/an-open-letter-to-the-hau-journals-boardof-trustees. 
Michael, Ann

2018 “Open Access Technology Options." Scholarly Kitchen, February 22. https:// scholarlykitchen.sspnet.org/2018/02/22/open-access-technology-options.

Mirowski, Philip

2018 "The Future(s) of Open Science." Social Studies of Science 48, no. 2: 171-203. https://doi.org/10.1177/0306312718772086.

Piron, Florence, et al.

2016 "Une autre science est possible: récit d'une utopie concrète dans la Francophonie (le projet SOHA)." Possibles 40, no. 2: 202-217. https://redtac.org/possibles/ 2017/02/11/une-autre-science-est-possible-recit-dune-utopie-concrete-dansla-francophonie-le-projet-soha.

Priem, Jason, and Bradley M. Hemminger

2012 “Decoupling the Scholarly Journal." Frontiers in Computational Neuroscience 6. https: / / doi.org/10.3389/fncom.2012.00019.

Tanis, Jonathan, ed.

2017 Margaret's Mead: Anthropological Inquiries into the Making and Sharing of Honey Wine. http: / / cultureandagriculture.americananthro.org/meadzine.

Tennant, Jonathan P., et al.

2017 "A Multidisciplinary Perspective on Emergent and Future Innovations in Peer Review [version 3; referees: 2 approved]." F1000 Research, November 29. https://doi.org/10.12688/f1000research.12037.3.

Todd, Zoe

2018 “The Decolonial Turn 2.0: The Reckoning.” Anthrodendum, June 15. https:// anthrodendum.org/2018/06/15/the-decolonial-turn-2-0-the-reckoning.

West, Paige, ed.

2018 "From Reciprocity to Relationality: Anthropological Possibilities." Hot Spots series, Cultural Anthropology website, September 26. https://culanth.org/ fieldsights/1525-from-reciprocity-to-relationality-anthropological-possibilities. 